\title{
Os paradoxos da Comunicação ante o Antropoceno
}

\author{
The paradoxes of Communication facing the Anthropocene
}

Les paradoxes de la Communication face à l'Anthropocène

\section{Dayana K. Melo da Silva}

Doutora em Sociologia pela Université Sorbonne Paris Cité, mestre em Comunicação e Culturas Midiáticas pela UFPB, com estágio Procad de mobilidade acadêmica na UFRJ, e graduada em Comunicação Social, com habilitação em jornalismo, pela UFPB. Atualmente, desenvolve pesquisa de pós-doutorado na ECA-USP.

\section{Carlos Eduardo Souza Aguiar}

Doutor em Sociologia pela Université Sorbonne Paris Cité, mestre em Ciências da Comunicação pela USP, especialista em Ciências da Religião pela PUC-SP e graduado em Filosofia e em Comunicação Social pela USP. É professor dos cursos de comunicação social e filosofia da Faculdade Paulus de Tecnologia e Comunicação (Fapcom).

\section{RESUMO}

O Antropoceno define a presente época da história geológica da Terra, na qual a superfície terrestre foi transformada pela ação humana. 0 termo também sugere uma convergência entre a história natural do planeta e a história social da humanidade. Inseridas nesse novo cenário, a Comunicação e as suas tecnologias se veem diante de complexos paradoxos. Ora essas tecnologias atuam na construção de uma consciência ecológica planetária, ao inaugurar novas possibilidades comunicativas, ampliando narrativas e articulando redes de identificação e solidariedade, ora elas intensificam a devastação do planeta por meio dos processos de produção, funcionamento e descarte de dispositivos midiáticos, cujo aspecto material não pode ser ignorado.

PALAVRAS-CHAVE: Comunicação; Antropoceno; Tecnologia; Pensamento Ecológico; Geologia da Mídia. 


\section{ABSTRACT}

The Anthropocene defines the current epoch of Earth's geological history, in which the Earth's surface was transformed by human action. The term also suggests a convergence between the natural history of the planet and the social history of humanity. Communication and its technologies, inserted in this new scenario, are faced with complex paradoxes. At the same time that these technologies act in the construction of a planetary ecological consciousness, by inaugurating new communicative possibilities, expanding narratives and articulating networks of identification and solidarity, they also intensify the devastation of the planet through the processes of production, operation and disposal of media devices, whose material aspect cannot be ignored.

KEYWORDS: Communication; Anthropocene; Technology; Ecological Thinking; Media Geology.

\section{RÉSUMÉ}

L'Anthropocène définit l'époque actuelle de l'histoire géologique de la terre, dans laquelle la surface terrestre a été transformée par l'action humaine. Le terme suggère également une convergence entre l'histoire naturelle de la planète et l'histoire sociale de l'humanité. Insérée dans ce nouveau scénario, la communication et ses technologies sont confrontées à des paradoxes complexes. En même temps que ces technologies agissent dans la construction d'une conscience écologique planétaire, en inaugurant de nouvelles possibilités de communication, en élargissant des récits et en articulant des réseaux d'identification et de solidarité, elles intensifient la dévastation de la planète par le biais de processus de production, de fonctionnement et d'élimination des dispositifs médiatiques, dont l'aspect matériel ne peut être ignoré.

MOTS-CLÉS: Communication; Anthropocène; Technologie; Pensée écologique; Géologie des médias.

\section{Introdução}

Ao despejar toneladas de dióxido de carbono na atmosfera por meio da queima de combustíveis fósseis, alterar os cursos dos rios, promover desmatamentos e queimadas, entre outras atividades, a humanidade transformou a superfície terrestre, impactando atmosfera e biosfera. Com isso, ela mudou a história geológica da Terra e inaugurou uma nova época chamada Antropoceno, que se define como o período no qual o homem, enquanto espécie, pela imensidade e intensidade das suas ações, tornou-se uma força de amplitude telúrica, rivalizando com as grandes forças da Natureza. 0 que também desencadeou um processo cumulativo e aparentemente irreversível de degradação das condições necessárias à nossa sobrevivência e à sobrevivência de outras espécies. 
As atividades humanas, mesmo nos períodos mais remotos, sempre influenciaram o ambiente, porém essa é a primeira vez na história da Terra que essa influência se dá no ambiente global, de modo a transformar completamente os ecossistemas ao seu redor e impactar consideravelmente o funcionamento do sistema terrestre como um todo (STEFFEN et al., 2011). A irônica contradição é que ao mesmo tempo em que a humanidade se torna umas das mais importantes forças geológicas, ela é incapaz de assumir um papel ativo na condução dos rumos da civilização. Por isso a leitura do Antropoceno como nossa época e condição: “O Antropoceno é o sinal da nossa potência, mas também da nossa impotência" (BONNEUIL; FRESSOZ, 2013, p. 9, tradução nossa).

Inseridas nesse novo cenário, a Comunicação e as suas tecnologias se veem diante de complexos paradoxos. Ao inaugurar novas possibilidades comunicativas, essas tecnologias atuam na construção de uma consciência ecológica planetária, ampliando narrativas e articulando redes de identificação e solidariedade - o que pode ser observado desde as mídias de massa até as mídias digitais. Por outro lado, os processos de produção dos aparatos e da infraestrutura digital, o custo energético de funcionamento desse sistema e o descarte desses dispositivos impactam o ambiente global de maneira intensa e contínua, apontando para a necessidade de incorporarmos ao pensamento comunicacional uma discussão acerca da materialidade dessas mídias.

Com base nessa leitura, buscaremos refletir a Comunicação de modo integrado aos desafios ambientais impostos pelo Antropoceno e pela iminência de um colapso ambiental global. Trata-se de uma abordagem que visa incorporar às múltiplas possibilidades comunicativas introduzidas pelas tecnologias da informação e comunicação os múltiplos impactos dessas mesmas tecnologias no ambiente natural. Assim, à capacidade dos dispositivos midiáticos de armazenar, processar e transmitir informações acresce-se a realidade material desses dispositivos, suas temporalidades e espacialidades. Uma dimensão da Comunicação que também dialoga com uma perspectiva ecológica das mídias, que as vê enquanto ambientes, ao mesmo tempo em que vê ambientes e elementos naturais enquanto mídias.

\section{Leituras do Antropoceno}

Dossiê o Pensamento Ecológico - https://revistaecopos.eco.ufrj.br/

ISSN 2175-8689 - v. 23, n. 2, 2020

DOI: 10.29146/eco-pos.v23i2.27530 
A palavra Antropoceno foi proposta pelo químico da atmosfera Paul Crutzen em fevereiro de 2000, durante o Colóquio do Programa Internacional da Geosfera-Biosfera, realizado na cidade mexicana de Cuernavaca, a fim de designar a presente época da história geológica da Terra (BONNEUIL; FRESSOZ, 2013). 0 termo aparece formalmente pela primeira vez em maio do mesmo ano, no artigo intitulado "The 'Anthropocene", escrito por Crutzen com a colaboração do biólogo Eugene Stoermer, que havia cunhado o vocábulo há cerca de duas décadas (CRUTZEN; STOERMER, 2000), sendo desenvolvido dois anos mais tarde em uma publicação na revista Nature (CRUTZEN, 2002). Os textos partem da ideia segundo a qual a ação humana transformou a superfície terrestre, e os impactos das atividades atuais continuarão por longos períodos.

Do ponto de vista geológico, tal hipótese sugere que, após o Pleistoceno, que abriu o Quaternário há 2,5 milhões de anos, e do Holoceno, que iniciou há 11.500 anos, a época atual pode ser nomeada de Antropoceno, do grego antigo ö $v \theta \rho \omega \pi \circ \varsigma$ (anthropos, "ser humano") e каıvós (kainos, "recente, novo"). 0 Antropoceno é, pois, a nova época dos humanos, caracterizando-se como o período no qual "A ação humana no ambiente global tornou-se tão vasta e ativa que ela rivaliza com algumas das grandes forças da Natureza em termos de impacto no funcionamento do sistema Terra" (STEFFEN et al., 2011, p. 842, tradução nossa).

Para Steffen et al, essa capacidade da civilização humana contemporânea de influenciar o meio ambiente em uma escala global fica evidenciada com as mudanças climáticas. Os pesquisadores destacam que, após a descoberta do buraco na camada de ozônio sobre a Antártida - consequência de ações antropogênicas -, a percepção de que a emissão de grandes quantidades de gases como o dióxido de carbono o (CO2) pode afetar o balanço de energia na superfície da Terra reforçou a preocupação acerca dos impactos das atividades humanas nos ecossistemas (STEFFEN et al., 2011, p. 842). Com isso, além das mudanças climáticas, os pesquisadores alertam para três outras grandes alterações provocadas pela ação humana:

Além do ciclo do carbono, os seres humanos estão (i) alterando significativamente vários outros biogeoquímicos, ou ciclos de elementos, como nitrogênio, fósforo e enxofre, que são fundamentais para a vida na Terra; (ii) modificando fortemente o ciclo da água terrestre, interceptando o fluxo dos rios dos planaltos para o mar e 
alterando o fluxo de vapor de água da terra para a atmosfera; e (iii) provavelmente conduzindo o sexto maior evento de extinção da história da Terra (STEFFEN et al., 2011, p. 843, tradução nossa).

Mesmo com a sua ampla aceitação pela comunidade de pesquisadores interessados em compreender as mudanças globais em curso, e presença nas narrativas e discursos midiáticos e de movimentos ecologistas, o termo Antropoceno ainda não foi formalmente aceito pela comunidade científica geológica. Há pouco mais de uma década, foi criado, dentro da Subcomissão de Estratigrafia Quaternária da Comissão Internacional de Estratigrafia, um grupo de trabalho internacional sobre o Antropoceno, o Anthropocene Working Group, com o objetivo de discutir se o termo deve ser reconhecido como uma nova época na história geológica da Terra. Em 2016, o grupo se reuniu durante o 35ํㅡ Congresso Geológico Internacional para avaliar a integração do termo; todavia, foram demandadas análises adicionais.

Ao criticar a procrastinação no reconhecimento do Antropoceno como a atual época, Bruno Latour, um dos pensadores do campo das ciências humanas e sociais engajados nas discussões sobre as mudanças climáticas e os impactos das ações humanas no ambiente global, ironiza:

Evidentemente, os geólogos necessitam de mais tempo para encontrar suficientes indícios reveladores do papel enormemente ampliado desse "antropos", cuja civilização consome cerca de 12 terawatts a todo instante e que está caminhando para cerca de 100 terawatts se o resto do mundo se desenvolver no nível dos Estados Unidos, um número impressionante se considerarmos que as forças das placas tectônicas devem produzir não mais que 40 terawatts de energia. 0 subcomitê acumula todos os dados dessa mudança abrupta de escala: como ele alterou o fluxo de todos os rios, o "antropos" é agora o fator de mudança mais significativo em todas as bacias hidrográficas do mundo; ele já é o principal agente na produção e distribuição do ciclo do nitrogênio; por meio do desmatamento, ele se tornou um dos principais fatores de erosão acelerada; e, é claro, seu papel no ciclo do carbono se torna tão imenso quanto o grau de sua cumplicidade no desaparecimento de espécies; a ponto de ser responsável pelo que é frequentemente chamado de "sexta extinção global" (LATOUR, 2014, p. 29, tradução nossa).

Note-se, ainda, que as discussões sobre a crescente influência da humanidade no ambiente global não são recentes, e algumas dessas análises são lidas como proféticas, como a feita por Buffon, em 1780, na obra Les Époques de la Nature, na qual ele afirma que

Dossiê 0 Pensamento Ecológico - https://revistaecopos.eco.ufrj.br/

ISSN 2175-8689 - v. 23, n. 2, 2020

DOI: 10.29146/eco-pos.v23i2.27530 
"A face inteira da Terra porta, hoje, a marca do poder humano" (BUFFON apud BONNEUIL; FRESSOZ, 2013, p. 18); ou pelo geólogo italiano Antonio Stoppani, em 1873, que, ao mencionar uma "era antropozoica", refere-se ao homem como uma "nova força telúrica que em poder e universalidade pode ser comparada com as maiores forças da terra" (STOPPANI apud CRUTZEN, 2002, p. 23). Outros trabalhos, como o de George Perkins Marsh, que intitula a segunda edição da sua obra Homem e Natureza (Man and Nature), de 1864, de A terra modificada pela ação humana (The Earth as Modified by Human Action), e o de Robert Lionel Sherlock, de 1922, intitulado Homem como agente geológico (Man as a geological agent), são igualmente significativos (STEFFEN et al., 2011, p. 844).

Do mesmo modo, no campo da filosofia também é possível observar uma antiga inquietação em relação aos impactos das ações humanas no planeta. Em dois manuscritos de Charles Fourier, considerado uma das principais figuras do socialismo crítico utópico, intitulados Deterioração material do planeta e Medicina Natural ou atraente composta, publicados, respectivamente, em 1847 e 1848, é notória a preocupação diante da deterioração do planeta como sintoma da ideia moderna de progresso (SCHÉRER, 2001). No primeiro deles, Fourier, que se opõe a pensadores como Saint-Simon, a quem acusa de defender um "falso progresso" que privilegia a "associação dos senhores" em detrimento dos "trabalhadores" e da "harmonia do planeta", alerta para a potência da ação humana na Terra: “[...] os céticos perguntam como um pigmeu como um homem poderia influenciar um colosso como a Terra? Eu já respondi que a estimativa do pigmeu é muito imprecisa [...] e que a raça humana que explora o globo é realmente maior do que o próprio planeta" (FOURIER, 2017, p. 5, tradução nossa).

Em direção semelhante está Eugène Huzar, que, em 1857, afirmou:

Em cem ou duzentos anos, o mundo, atravessado por ferrovias, barcos a vapor, coberto de usinas, fábricas, liberará trilhões de metros cúbicos de ácido carbônico e monóxido de carbono, e como as florestas terão sido destruídas, essas centenas de trilhões de ácido carbônico e monóxido de carbono podem muito bem perturbar um pouco a harmonia do mundo (HUZAR apud FRESSOZ, 2010, p. 98, tradução nossa).

De acordo com Jean-Baptiste Fressoz (2010), a proposição de Huzar pode ser lida como sendo, provavelmente, a primeira teoria do catastrofismo tecnológico. Tanto 
Fourier como Huzar são contemporâneos de um período de grande entusiasmo em relação aos avanços tecnocientíficos. As suas análises se dão quase um século após o início da Revolução Industrial e a invenção da máquina a vapor de James Watt, em 1784. E é justamente nesse período que, de acordo com Crutzen, teve início o Antropoceno: "Podese dizer que o Antropoceno começou na última parte do século XVIII, quando as análises do ar retido no gelo polar mostraram o início de crescentes concentrações globais de dióxido de carbono e metano" (CRUTZEN, 2002, p. 23, tradução nossa). Assim como Crutzen, para os climatologistas Will Steffen e Claude Lorius, a chave para o entendimento empírico dessa mudança epocal na geologia da Terra está no ar: “[...] eis que a análise do ar contido nos gelos nos mostra brutalmente que a mão do homem, ao inventar a máquina a vapor, desregulou, ao mesmo tempo, a máquina do mundo" (LORIUS; CARPENTIER, 2010, p. 11, tradução nossa).

Sobre a relação entre o surgimento da máquina a vapor e a emergência de uma nova época, também é profética a afirmação de Henri Bergson, que na célebre obra L'Évolution Créatrice, de 1907, escreveu: “Um século se passou desde a invenção da máquina a vapor, e apenas começamos a sentir o profundo abalo que ela nos causou [...] Em milhares de anos, quando ao olharmos para o passado e só percebermos as grandes linhas, nossas guerras e revoluções contarão pouco, mesmo supondo que sejam lembradas"; e acrescenta afirmando que, da máquina a vapor, bem como todos os tipos de invenções que a acompanharam, ao contrário, “[...] talvez falemos como falamos do bronze ou da pedra lascada; ela servirá para definir uma idade [...] talvez não diremos Homo sapiens, mas Homo faber" (BERGSON, 2007, p. 99-100, tradução nossa).

Steffen et al citam a influência de Bergson nos trabalhos de Vladimir Vernadsky e Pierre de Chardin, que, junto com Edouard Le Roy, propuseram na década de 1920 a ideia de evolução da biosfera e a sua transformação em noosfera. Tal concepção influenciou, por sua vez, parte dos debates que ocorreram em meados do século passado acerca da amplitude e intensidade das ações humanas no ambiente global. Os autores também mencionam o russo Vernadsky e o americano Henry Adams como os únicos a imaginar o que eles chamam de a "Grande Aceleração da segunda fase do Antropoceno", que se deu no pós-Segunda Guerra Mundial, e é caracterizada pela “[...] industrialização mundial, 
desenvolvimento técnico-científico, corrida armamentista nuclear, explosão populacional e rápido crescimento econômico" (STEFFEN et al., 2011, p. 845, tradução nossa).

Todavia, conforme complementam Steffen et al, tanto a ideia de noosfera como as ideias anteriores semelhantes a ela não são equivalentes ao atual conceito de Antropoceno (STEFFEN et al., 2011, p. 845, tradução nossa). Elas tampouco se equivalem a outros termos surgidos posteriormente para descrever a presente época, a exemplo do termo Capitaloceno, que tira a responsabilidade central da humanidade na devastação do globo e a coloca no sistema capitalista (HARAWAY, 2015; MOORE, 2016). O que também indica um entrelaçamento entre história natural e história humana ou social, como bem demostram, de modos não necessariamente convergentes, Dipesh Chakrabarty (2009, p. 222) - que apresenta uma nova ideia de universal nascida de um "senso compartilhado de catástrofe" - e Rémi Beau e Catherine Larrère - que argumentam que "Pela primeira vez na história do planeta, uma época geológica seria definida pela capacidade de ação de uma espécie, a espécie humana. É assim que a grande narrativa do encontro entre a história social dos homens e a história natural do planeta toma forma" (BEAU; LARRÈRE, 2018, p. 8, tradução nossa).

A atual concepção de Antropoceno coloca a questão das alterações climáticas de modo relacionado à degradação da biosfera, e a estende a questionamentos sociológicos e filosóficos sobre o capitalismo, a geopolítica e o papel da tecnologia e da ciência moderna nesse processo. Tudo isso ao mesmo tempo em que se interroga acerca da data precisa da nossa entrada nele ou da sua entrada no mundo: se a partir do século XVIII - período no qual, conforme evidenciam Crutzen e Steffen (2003), teve início uma das mais significativas transformações nas estruturas geológicas e climáticas da Terra executada pela espécie humana - ou mesmo anteriormente, seja com o início da agricultura extensiva há 8.000 anos, seja com a invasão do dito "Novo Mundo" pelos europeus, em 1492; ou se apenas em 1945, com os testes e explosão da bomba atômica, entre outras proposições (LEWIS; MASLIN, 2015).

Outro questionamento ainda em aberto é quem deve ser responsabilizado pelo Antropoceno: se toda a espécie humana, se apenas o homem branco ocidental, se o sistema econômico capitalista, ou se a técnica moderna. De qualquer modo, como bem alerta Peter Sloterdijk (2015), o Antropoceno, apesar de estar inserido em um habitus 
epistemológico característico do século XIX - que busca historicizar qualquer objeto arbitrário e classificar todos os campos historicizados em eras, idades e épocas -, inverte a lógica moderna, observando o tempo a partir do fim. Note-se, assim, que pensar com base na imagem do Antropoceno significa também pensar com base nas noções de tempo e espaço.

\section{As tecnologias de comunicação e a transparência do colapso}

Concomitantemente aos debates que se deram a partir da segunda metade do século XX acerca dos impactos da ação humana no ambiente global, observamos o surgimento de uma consciência ecológica planetária, associada, em grande medida, aos movimentos de conservação da Natureza. Esses movimentos emergem do mesmo espírito contestador da contracultura e se desenvolvem no decorrer dos anos setenta, indicando uma nova relação entre pessoas e meio ambiente manifestada de maneiras distintas. Isso fez com que a ecologia saísse do domínio exclusivamente científico e se tornasse um campo de forças e de construção de narrativas políticas e ações coletivas diretas, como as protagonizadas por ativistas ambientalistas confrontando o poder de Estados e empresas multinacionais ${ }^{1}$

Outro fator de destaque é o contexto de comunicação generalizada, tal como descrito por Gianni Vattimo. Seguindo o argumento do filósofo, veremos que "no nascimento de uma sociedade pós-moderna um papel determinante é desempenhado pelos mass media"; estes, por sua vez, "caracterizam esta sociedade não como uma sociedade mais 'transparente', mais consciente de si, mais 'iluminada', mas como uma sociedade mais complexa, até caótica", e "é precisamente nesse relativo 'caos' que residem as nossas esperanças de emancipação" (VATTIMO, 1992, p. 10). Na tese de Vattimo, os meios de comunicação de massa, como rádio, jornal e televisão, propiciaram uma multiplicação de visões e imagens de mundo, uma tomada de palavra por minorias historicamente silenciadas e reprimidas.

\footnotetext{
${ }^{1}$ Como exemplo de organização que promove esse tipo de ação, cuja difusão midiática é fundamental para o processo de legitimação, está o Greenpeace, criado em 1971 (OLLITRAULT, 1999).
}

\section{Dossiê 0 Pensamento Ecológico - https://revistaecopos.eco.ufrj.br/}


Com base nessa leitura, podemos afirmar que o surgimento e desenvolvimento das Tecnologias da Informação e Comunicação (TICs) complexificou ainda mais esse processo. Os sites e redes sociais proporcionaram, em um primeiro momento, o aparecimento de verdadeiras comunidades de interação social no contexto digital (CASTELLS, 2003). Com a proliferação das mídias móveis e locativas e a integração da informática na vida cotidiana, um novo ecossistema comunicacional, tecnológico e midiático se constituiu, fazendo com que as interações se tornassem mais equipadas e ampliadas, permitindo novas formas de ativismos e mobilizações (CASTELLS, 2012). Um outro fator de destaque é o continuum e o hibridismo entre espaços e territórios físicos e digitais-informacionais engendrados por esses dispositivos e suas arquiteturas (SILVA, 2006).

O que queremos dizer com isso é que os movimentos ecologistas e suas variadas formas de manifestação, mesmo aquelas que se colocam em uma posição anti-tecnologia, emergiram em um contexto tecnológico e comunicacional distinto, sendo por ele impulsionados. Desde as mídias de massa até as mídias digitais, esses movimentos mobilizam as tecnologias direta ou indiretamente a fim de expandir as suas narrativas e/ou construir redes de identificação locais e globais. Estratégias que, em razão da própria natureza ubíqua e pervasiva do digital, são atualmente acrescidas de uma inter-relação entre os ambientes social, tecnológico e natural, estabelecendo um novo elo humanidadetecnologia-território.

Ao observamos o contexto brasileiro da última década, encontraremos uma pluralidade de casos exemplares, muitos deles já analisados com base em uma perspectiva comunicacional, como os movimentos de ocupação de praças, parques e ressignificação de espaços urbanos, que utilizam as tecnologias digitais e em rede para disseminar informações e engajar novos colaboradores; as crescentes comunidades de hortas e hortelãos urbanos e de trocas de sementes; e mesmo os coletivos de revitalização de nascentes, rios e córregos, como os que atuam na cidade de São Paulo, que utilizam essas tecnologias tanto para produção e compartilhamento de informações acerca das suas atividades e projetos quanto para mapear os cursos de água retificados, canalizados e enterrados sob as ruas e avenidas da cidade (SILVA, 2019). 
Os povos indígenas no Brasil também se configuram como exemplos dessas redes de relação mútua, ao buscar mobilizar as tecnologias digitais na luta pelo território e pela vida. É o caso dos Guarani Kaiowá de Pyelito Kue/Mbarakay, comunidade localizada no estado do Mato Grosso do Sul, que por meio de uma página na rede social Facebook², encontrou uma maneira de denunciar os abusos sofridos e articular redes de resistência e solidariedade, publicando cartas direcionadas ao povo brasileiro e às instituições governamentais federais. Entre essas cartas está a que deu origem à mobilização "Somos todos Guarani Kaiowá” e "Sou Guarani Kaiowá" (\#SomosTodosGuaraniKaiowa \#SouGuaraniKaiowa), entendida pelos indígenas como uma voz sagrada e protetora ${ }^{3}$. Tal mobilização fez com que vários brasileiros e mesmo estrangeiros trocassem seus sobrenomes no Facebook pelo nome da etnia Guarani Kaiowá (OLIVEIRA; BENITES; NETO, 2016).

Conexões semelhantes também podem ser identificadas no processo de autodemarcação iniciado em 2014 pelos Munduruku do território Daje Kapap Eypi, que atende às populações do Médio e Alto Tapajós, no estado do Pará. Utilizando facões, enxadas e dispositivos digitais conectados ao Sistema de Posicionamento Global (GPS), os Mundukuru espalham estacas na floresta visando delimitar a sua Terra Indígena. Todas essas ações, bem como as denúncias de invasão e exploração do território por madeireiros, são compartilhadas pelos Mundukuru em sites ${ }^{4}$ e redes sociais ${ }^{5}$. Em 2018, os indígenas também criaram uma plataforma digital chamada "Mapa da Vida", que consiste em um mapeamento territorial e cultural ${ }^{6}$.

Há ainda o exemplo dos Ka'apor da Terra Indígena Alto Turiaçu, uma das últimas extensões de floresta amazônica no estado do Maranhão. Com a colaboração do Greenpeace, eles criaram em 2015 um sistema autônomo de vigilância do território que utiliza rastreadores via satélite e tecnologias para fotografar e mapear possíveis invasões. O objetivo das armadilhas fotográficas é registrar as operações de extração de madeira. Esses dispositivos são ativados por meio de sensores de movimento e temperatura, sendo

\footnotetext{
2 Disponível em: https://web.facebook.com/aty.guasu/ Acesso em: 10 abr. 2020.

${ }^{3}$ Disponível em: http://campanhaguarani.org/?tag=aty-guasu Acesso em: 10 abr. 2020.

${ }_{4}^{4}$ Disponível em: https://autodemarcacaonotapajos.wordpress.com/ Acesso em: 11 abr. 2020.

${ }^{5}$ Disponível em: https://web.facebook.com/amazonyaemchama/ Acesso em: 11 abr. 2020.

${ }^{6}$ Disponível em: https://br.heartoftheamazon.org/omapadavida/ Acesso em: 11 abr. 2020.
} 
capazes de capturar imagens diurnas e noturnas. Já os rastreadores permitem seguir o curso da madeira ilegal nos caminhões dos madeireiros e enviar informações contínuas acerca das rotas percorridas, que são observadas por meio de APIs (Application Programming Interfaces) de geolocalização ${ }^{7}$.

Ademais, a tecnologia, em sua forma digital e em rede, também atua para revelar elementos do território físico transformados por atividades humanas, como o desmatamento. Utilizando Sistemas de Informação Geográfica (SIGs), tecnologias de sensoriamento remoto, tecnologias de processamento em nuvem e classificadores automatizados desenvolvidos e operados com base na plataforma Google Earth Engine, pesquisadores do MapBiomas (Projeto de Mapeamento Anual da Cobertura e Uso do Solo do Brasil) atuam, desde 2015, na geração de mapas interativos com informações sobre a cobertura e uso do solo no Brasil, possibilitando o acesso a dados sobre desmatamento, regeneração, cobertura e qualidade do solo em todos os biomas brasileiros, bem como a sua comparação entre períodos distintos ${ }^{8}$.

Sobre essa integração da técnica na vida de "terranos" e "humanos", distinção proposta por Latour (2015), os pensadores brasileiros Déborah Danowski e Eduardo Viveiros de Castro enfatizam que é preciso considerar que a interpretação moderna da técnica - e, portanto, sua essência "onto-antropológica", instrumento do triunfo da história - não é exclusiva e nem absoluta:

Pois existem técnicas terranas como existem técnicas humanas, distinção que não se reduz a simples questão do comprimento de suas redes. A guerra entre os Terranos e os Humanos será travada essencialmente nesse plano, especialmente quando incluímos, na categoria ampliada e pluralizada das técnicas, toda uma gama de "desvios" sociotécnicos e de invenções institucionais muito antigas ou ao contrário muito recentes: a organização horizontal e a tática "Black Bloc" dos movimentos de protesto anti-globalização, os sistemas de parentesco e mapas totêmicos australianos, as formas de mobilização e de comunicação criadas pela Internet, as redes de trocas de sementes tradicionais na Índia ou no Brasil, os sistemas de crédito informal do tipo hawala. Toda inovação técnica crucial para a "resiliência" da espécie não precisa necessariamente passar pelos canais corporativos da Big Science ou pelas muito longas redes de humanos e não

\footnotetext{
${ }_{7}$ Disponível em: https://www.greenpeace.org/brasil/blog/povo-indigena-kaapor-integra-tecnologia-nomonitoramento-e-protecao-do-seu-territorio-tradicional/ Acesso em: 11 abr. 2020.

${ }^{8}$ Disponível em: https://mapbiomas.org/ Acesso em: 13 abr. 2020
}

Dossiê 0 Pensamento Ecológico - https://revistaecopos.eco.ufrj.br/ 
humanos mobilizados pelo desenvolvimento das "tecnologias de ponta" (DANOWSKI; CASTRO, 2014, p. 312-313, tradução nossa).

Enfatizando o aspecto revelador da tecnologia, não podemos esquecer que foi exatamente por meio da televisão que a humanidade pôde, pela primeira vez, ver a Terra a partir de uma posição exterior a ela. Uma ideia de exterioridade que, ao lado da ideia de Natureza ilimitada, pode ter impulsionado o processo de objetificação do planeta e do ambiente natural. Por isso a necessidade de articular novos caminhos para entender as complexidades ecológicas e tecnológicas da atualidade.

\section{A obscenidade das tecnologias de comunicação}

Pensar a Comunicação de modo complexo significa agregar aos seus estudos uma abordagem que leve em conta não apenas as novas possibilidades comunicativas, de transparência e de participação na vida social inauguradas pelas tecnologias digitais e em rede, inclusive aquelas que dizem respeito ao ativismo ecológico, mas também a questão das materialidades dessas novas mídias, que continuam, de modo cada vez mais intenso, a pôr a Natureza no sentido do requerer. Essas tecnologias formam uma rede global que envolve terminais, smartphones, computadores, tablets etc., que se conectam por meio de infraestruturas de rede constituídas por cabos terrestres e submarinos, antenas, redes móveis, fibra óptica, entre outros elementos, a fim de trocar informações armazenadas e processadas em data centers. Cada um desses elementos requer energia não apenas para funcionar - a fase de uso - mas, antes disso, para serem produzidos. A mineração de matérias-primas, os processos industriais e a entrega aos consumidores exigem recursos substanciais.

Trata-se de um impacto contínuo que envolve a produção dos aparatos e da infraestrutura digital e o custo energético do funcionamento desse sistema. Sem esquecer do impacto do descarte, no qual o obsoleto, o descartável e o lixo eletrônico intensificam os processos degradadores. A chamada cultura digital, apesar do imaginário da imaterialidade, é dependente de energia e materiais, de modo que as mídias e a Terra estão intimamente conectadas. 
Evidencia-se, assim, que não podemos refletir seriamente sobre o digital sem direcionar o olhar à reconexão entre mídia e Natureza, como bem ressalta John Peters:

À luz da possível ameaça irreversível ao nosso habitat pela mudança climática e pela explosão de dispositivos digitais, tanto pela sobrecarga de carbono na atmosfera quanto dos dados superabundantes na 'nuvem', é salutar reabrir a relação das mídias com a natureza" (PETERS, 2015, p. 1, tradução nossa)

Trata-se de uma parte obscena da nossa cultura midiática, como bem designou Jussi Parikka (2015). Essa dimensão complexa das tecnologias de comunicação merece ser refletida com base em uma abordagem ecológica que vai em direção aos objetos e à técnica. São os próprios dispositivos digitais que nos obrigam a pensar as mídias como ambiente, e é justamente a perspectiva ecológica das mídias que chama a atenção para esse duplo aspecto, tanto rejeitando o caráter instrumental das mídias, na medida em que essas constituem o nosso ambiente (FULLER, 2005; MCLUHAN, 1970; MEYROWITZ, 1985), como ressaltando o próprio impacto desses aparatos no mundo natural (BRATTON, 2015; PARIKKA, 2015a; PETERS, 2015).

É a própria hipótese do Antropoceno que nos conduz a essa atenção extra sobre a Terra, de modo que a abordagem arqueológica da Comunicação é ainda mais necessária, não somente por relativizar o mito do progresso teleológico das mídias, como já nos alertava Siegfried Zielinski (2006), mas, sobretudo, porque a materialidade desses novos aparatos faz apelo a um tempo profundo no sentido mais intenso do termo: os materiais que são extraídos das profundezas terrestres e que permitem o funcionamentos desses aparelhos (PARIKKA, 2015a). O que evidentemente faz aumentar a chamada pegada humana no planeta. A cultura digital inicia-se nas profundezas. Parikka expande a análise acerca do tempo profundo das mídias, tal como proposta por Zielinski, em direção aos tempos não humanos, passado e presente. Com isso, ele busca complexificar a arqueologia das mídias propondo uma geologia das mídias. Uma mudança não apenas na perspectiva espacial, mas também na perspectiva temporal.

Parikka visa estender a noção de materialidade das mídias na direção das materialidades profundas e tempos profundos. No limite, para compreender adequadamente as mídias contemporâneas devemos, antes, compreender as realidades 
materiais que precedem a própria mídia, isto é, a história da Terra, suas formações geológicas, seus minerais etc. É precisamente a perspectiva arqueológica que teimosamente questiona a materialidade dos dispositivos que, por milênios, nos permitem gravar, transmitir e processar informações. Uma busca pela profundidade não apenas como o índice de um tempo profundo, mas também como recurso no sentido heideggeriano.

Vale lembrar que, para Heidegger, a essência da técnica, que não é nada de técnico, não está ligada a uma prática, mas a uma maneira de desvelar o mundo. Nessa relação de desvelamento, há uma ação que pertence à produção, própria da técnica antiga, e aquela que pertence à provocação, característica da moderna tecnologia das máquinas. A essência da técnica moderna se encontra na armação, isto é, na conversão da natureza em mera fonte de energia:

O desabrigar que domina a técnica moderna tem o caráter do pôr no sentido do desafio. Este acontece pelo fato de a energia oculta na natureza ser explorada, do explorado ser transformado, do transformado ser armazenado, do armazenado ser novamente distribuído e do distribuído renovadamente ser comutado. Explorar, transformar, armazenar e distribuir são modos de desabrigar (HEIDEGGER, 2007, p. 382).

À época da informática das nuvens, é salutar, portanto, ter em conta os aspectos materiais irrefragáveis, notadamente o contexto ambiental e a questão do consumo de energia, que não nos fazem esquecer que nossos aparatos digitais continuam dentro desse modo de desvelamento destacado por Heidegger. A exigência da constante inovação e do novo da economia digital representa, assim, um ciclo nefasto de devastação:

O novo não pode nascer a menos que algo seja descartado, jogado fora ou destruído. 0 novo é criado no curso de uma meticulosa e impiedosa dissociação entre o produto-alvo e tudo mais que se coloque no caminho de sua chegada. Preciosos ou de pouco valor, metais puros podem ser obtidos apenas removendose a escória e o borralho do minério. E só se pode chegar ao minério removendose e depositando-se camada após camada do solo que impede o acesso ao veio tendo-se primeiro cortado ou queimado a floresta que impedia o acesso ao solo (BAUMAN, 2005, p. 31).

Dossiê 0 Pensamento Ecológico - https://revistaecopos.eco.ufrj.br/

ISSN 2175-8689 - v. 23, n. 2, 2020

DOI: 10.29146/eco-pos.v23i2.27530 
O planeta é, no limite, a condição da mídia, sendo ele mesmo uma mídia, um tipo de dispositivo de registro (PETERS, 2015). Assim, segundo Peters, apesar de durante o século XX o conceito de mídia estar mais associado às ferramentas tecnológicas de disseminação de informações em massa, tal conceito não perdeu completamente o seu caráter original ambiental, ou seja, de mídia como meio. A hipótese do Antropoceno deixa evidente a urgência da proposição de Peters, que diz que se podemos considerar a mídia como um ambiente, também é possível considerar o meio como uma mídia:

A velha ideia de que as mídias são ambientes pode ser invertida: ambientes também são mídias. Água, fogo, céu, terra e éter são elementos - acolhedores, sublimes, perigosos e maravilhosos - que sustentam as existências, e ainda não descobrimos como cuidar deles; nossos esforços para fazer isso constituem nossa história técnica (PETERS, 2015, p. 3, tradução nossa).

É essa contradição do nosso tempo que Peters destaca; afinal, podemos ver o digital como um meio de existência, de certa forma similar à água, ar, terra, fogo e éter em suas configurações básicas como ambientes, o que coaduna-se com a sensibilidade teórica de Parikka de conectar a história da Comunicação e de suas tecnologias a fases anteriores da montagem dos aparatos. Os próprios dados estatísticos sobre o uso dos minerais são reveladores, sobretudo com o aumento, por volta da década de 1990, do consumo do metal índio, e o aumento do consumo de silício e de raros minerais desde a década de 1950

Se eles são ou não percebidos em termos de mídia, são os recursos do tempo profundo da Terra que fazem a tecnologia acontecer. 0 surgimento da geologia como disciplina desde os séculos XVIII e XIX, bem como as técnicas de mineração desenvolvidas desde então são essenciais para a cultura midiática-tecnológica (PARIKKA, 2015b, p. 8, tradução nossa).

Parikka busca pensar em algumas das consequências do que poderia implicar uma compreensão mais ambiental, ecológica e bio-filosófica das mídias. Nesse contexto, a mídia é considerada como um campo de força, uma potencialidade, um ponto de interseção em que as forças se contraem para formar certos potenciais de afetos e percepções. Conectando mídia e planeta, Parikka retoma a alegação de Deleuze e Guattari

Dossiê 0 Pensamento Ecológico - https://revistaecopos.eco.ufrj.br/

ISSN 2175-8689 - v. 23, n. 2, 2020

DOI: 10.29146/eco-pos.v23i2.27530 
de que a terra é um ente vivo, de modo que as profundezas da Terra são lugares essenciais para a emergência da cultura técnica e midiática contemporânea: "A história da mídia conflita com a história da terra; o material geológico de metais e produtos químicos é desterritorializado de seus estratos e reterritorializado em máquinas que definem nossa cultura tecno-midiática" (PARIKKA, 2015b, p. 18, tradução nossa).

A crescente produção de smartphones e tablets esgotarão em breve as reservas minerais acumuladas em milhões de anos e extraídas pela mão de obra barata de países pobres. Fica evidente, portanto, que as tecnologias não podem ser tomadas apenas como ferramentas ou instrumentos oriundos de materiais sólidos, mas como meios pelos quais a Natureza é expressa e alterada (PETERS, 2015). Toda transferência tecnológica de informação representa um dispêndio de energia:

A computação nunca é termodinamicamente livre; qualquer ato de organização intelectual corre contra a tendência de tudo se degradar. A necessidade de resfriamento sempre estabeleceu limites para o design computacional, especificamente sobre o quão densamente os componentes podem ser compactados. A noosfera requer uma infraestrutura. Talvez o registro angélico seja irrestrito pelo calor, mas o Google, apesar de suas pretensões, é muito mais um meio terrestre do que um meio celeste ou oceânico, qualquer um dos quais obviamente preferiria ser. Há muita sujeira nos dados. Muita computação depende do carvão e do coltan, e estima-se que os data centers usem de 1 a $3 \%$ da produção elétrica (PETERS, 2015, p. 333, tradução nossa).

Sabemos que, em geral, a nossa pegada ecológica relacionada à digitalização está crescendo, embora seja difícil a sua mensuração. Ao lado do impacto ligado à produção dos aparelhos e infraestrutura, é fundamental levar em consideração o custo energético do setor digital, que já corresponde a $4 \%$ das emissões de gases de efeito estufa, acelerando a cada ano em 9\%. Atualmente, ele já representa um impacto maior do que o da aviação civil, e a projeção é de que até 2025 supere o setor automotivo, segundo dados publicados no relatório The Shift Project ${ }^{9}$ que demonstra que as tendências do consumo digital são insustentáveis.

\footnotetext{
${ }^{9}$ The Shift Project. Lean ICT: towards digital sobriety-report of the working group directe by Hugues Ferreboeuf for the Think Tank The Shift Project. March, 2019. Disponível em: https://theshiftproject.org/wp-content/uploads/2019/03/Lean-ICT-Report The-ShiftProject 2019.pdf. Acesso em: 09 jun. 2020.
}

Dossiê 0 Pensamento Ecológico - https://revistaecopos.eco.ufrj.br/ 
Apesar dessas evidências, o vocabulário tecnopolítico tem enfatizado a imaterialidade da digitalização, como os serviços de armazenamento em nuvem. Camuflase por detrás desse imaginário um impacto ecológico desastroso: somente os serviços em nuvem, se tomados em seu conjunto, consomem mais energia do que países como Brasil ou França (BRATTON, 2015). Imaterialidade, portanto, apenas aparente, pois existem cabos submarinos, terras raras, minerais e data centers, ou seja, toda uma infraestrutura necessária para a economia digital. De acordo com Benjamin Braton: "Estima-se que a eletricidade necessária para enviar trilhões de e-mails de spam em todo o mundo a cada ano seja equivalente à necessária para alimentar dois milhões de residências americanas, e que gere a mesma quantidade de gases de efeito estufa que três milhões de carros" (BRATTON, 2015, p. 93, tradução nossa.). Estamos acumulando verdadeiros aterros sanitários não só de lixo eletrônico, mas de lixo digital, como os trilhões de spams que precisam ser armazenados em algum lugar.

O acréscimo da obscenidade no conceito de Antropoceno é, portanto, autoexplicativo: "Podemos nos lembrar das consequências ambientalmente desastrosas da obsolescência programada dos meios eletrônicos, dos custos energéticos da cultura digital e, por exemplo, dos arranjos neocoloniais de extração de material e energia em todo o mundo" (PARIKKA, 2015b, p. 10, tradução nossa). A materialidade das tecnologias de comunicação e suas infraestruturas começa no solo e no subsolo, explorando as diferentes camadas do sistema Terra. 0 funcionamento de toda a cultura digital requer energia extraída da Natureza. Sem falar em todo o impacto provocado pelo lixo eletrônico de nossos hardwares inúteis após findado o seu ciclo de obsolescência programada, materialidades que retornam à Natureza, intensificando a poluição ambiental.

\section{Considerações Finais}

Ao mesmo tempo em que desvelam de modo nítido a dimensão da catástrofe ambiental, sobretudo com as ferramentas de monitoramento e os diferentes ativismos digitais, as tecnologias da informação e comunicação colaboram - por seu custo energético de produção e funcionamento e impacto do descarte - com a devastação planetária. Eis um dos muitos paradoxos da Comunicação ante o Antropoceno, época de 
saturação da ideia moderna de Natureza como um fundo infinito de recursos a serem extraídos pela imagem cartesiana de homem como senhor e possuidor da Natureza. É justamente a constatação desse paradoxo que nos incita a sair de uma antiga e persistente dicotomia teórica que separa apocalíticos e integrados.

$\mathrm{Na}$ aparente contradição das teses e absoluta identidade dos fins, essas posições concebem a técnica na chave da instrumentalidade. Um instrumento que ora corrompe o planeta, provocando o Antropoceno ou mesmo o "Tecnoceno", ora representa a realização da utopia da emancipação e o melhoramento da sociedade, que se torna cada vez mais consciente dos seus problemas. Abandona-se a perspectiva instrumental e abre-se toda uma dimensão complexa das mídias e das tecnologias de comunicação como modos de existência que co-determinam nossa maneira de ser e estar no mundo e que, portanto, provocam consequências conflitantes e paradoxais.

A Comunicação, enquanto um campo de pensamentos e práticas, deve aceitar suas complexidades e paradoxos, consciente do seu compromisso de disseminação da gravidade disso que Isabelle Stengers (2009) chama de "intrusão de Gaia", na forma da comunicação ambiental, e de conexão de diferentes atores engajados na construção de novas formas de habitar o mundo. Ao mesmo tempo, ela deve assumir uma postura de sobriedade diante do ritmo das atualizações tecnológicas. Se, doravante, o ambiente muda mais rápido do que a sociedade, a Comunicação deve pautar-se por uma ética da precaução que leve em conta imprevistos e impactos, na qual se introduz valores como a questão da sustentabilidade, da justiça socioambiental e da reciprocidade interespécies, próximo ao que é preconizado pelo princípio de responsabilidade de Hans Jonas (2017), sabendo dizer sim ou não à técnica - aquilo que Martin Heidegger (1968) chamou de serenidade. Trata-se de um olhar para a cultura midiática e comunicacional considerando o impacto das suas tecnologias no planeta, sem, com isso, cair no reducionismo da rejeição.

\section{Referências bibliográficas}

BAUMAN, Z. Vidas desperdiçadas. Rio de Janeiro: Jorge Zahar, 2005.

BEAU, R.; LARRÈRE, C. (Org.). Penser l'Anthropocène. Paris: Les Presses Sciences Po ; Fondation

\section{Dossiê 0 Pensamento Ecológico - https://revistaecopos.eco.ufrj.br/}


de l'écologie politique, 2018.

BERGSON, H. L'évolution créatrice. Paris: Puf, 2007.

BONNEUIL, C.; FRESSOZ, J.-B. L'événement Anthropocène : La Terre, l'histoire et nous. Paris Genève: Le Seuil, 2013.

BRATTON, B. H. The stack: on software and sovereignty. Cambridge, Massachusetts: MIT Press, 2015.

CASTELLS, M. Networks of outrage and hope: social movements in the Internet Age. Cambridge, UK ; Malden, MA: Polity Press, 2012.

The Internet Galaxy: reflections on the internet, business, and society. Oxford: Oxford Univ. Press, 2003.

CHAKRABARTY, D. The Climate of History: Four Theses. Critical Inquiry, v. 35, n. 2, p. 197-222, 2009.

CRUTZEN, P. J. Geology of mankind. Nature, v. 415, n. 6867, p. 23-23, 2002.

CRUTZEN, P. J.; STOERMER, E. F. The “Anthropocene”. Global Change Newsletter, n. 41, p. 17-18, 2000.

CRUTZEN, P. J.; STEFFEN, W. How long have we been in the Anthropocene era?. Climatic Change, v. 61, n. 3, p. 251-257, 2003.

DANOWSKI, D.; CASTRO, E. V. DE. L'arrêt de monde. In: HACHE, É. (Org.). De l'univers clos au monde infini. Paris: Dehors, 2014. p. 221-339.

FOURIER, C. Détérioration matérielle de la planète. EcoRev', v. 44, n. 1, p. 4-8, 2017.

FRESSOZ, J.-B. Eugène Huzar et l'invention du catastrophisme technologique. Romantisme, v. 150 , n. 4 , p. $97-103,2010$.

FULLER, M. Media ecologies: materialist energies in art and technoculture. Cambridge, Mass.: MIT Press, 2005.

HARAWAY, D. Anthropocene, Capitalocene, Plantationocene, Chthulucene: Making Kin. Environmental Humanities, v. 6, n. 2015, p. 159-165, 2015.

HEIDEGGER, M. A questão da técnica. scientiæ studia, v. 5, n. 3, p. 375-398, 2007.

Sérénité. Questions III et IV. Paris: Gallimard, 1968.

JONAS, H. Une éthique pour la nature. Paris: Flammarion, 2017.

LATOUR, B. Face à Gaïa. Paris: La Découverte, 2015.

. L'Anthropocène et la destruction de l'image du Globe. In: HACHE, É. (Org.). De l'univers clos au monde infini. Paris: Dehors, 2014. p. 27-54.

LEWIS, S. L.; MASLIN, M. A. Defining the Anthropocene. Nature, v. 519, n. 7542, p. 171-180, 2015.

Dossiê 0 Pensamento Ecológico - https://revistaecopos.eco.ufrj.br/

ISSN $2175-8689$ - v. 23, n. 2, 2020

DOI: 10.29146/eco-pos.v23i2.27530 
LORIUS, C.; CARPENTIER, L. Voyage dans l'anthropocène: cette nouvelle ère dont nous sommes. Arles: Actes Sud, 2010.

MCLUHAN, M. Education in the electronic age. Interchange, v. 1, n. 4, p. 1-12, 1 dez. 1970.

MEYROWITZ, J. No sense of place: the impact of electronic media on social behavior. New York: Oxford University Press, 1985.

MOORE, J. W. (Org.). Anthropocene or capitalocene? nature, history, and the crisis of capitalism. Oakland, CA: PM Press, 2016.

OLIVEIRA, L. de; BENITES, T.; NETO, R. de O. Sacrifício e quase-acontecimento: apontamentos sobre a visibilidade da luta pela terra dos povos indígenas Guarani e Kaiowa. Cadernos de História, v. 17, n. 26, p. 114-142, 2016.

OLLITRAULT, S. De la caméra à la pétition-web : le répertoire médiatique des écologistes. Réseaux, n. 98, p. 153-185, 1999.

PARIKKA, J. A geology of media. Minneapolis ; London: University of Minnesota Press, 2015a.

The anthrobscene. Minneapolis: Univ. of Minnesota Press, 2015b.

PETERS, J. D. The marvelous clouds: toward a philosophy of elemental media. Chicago ; London: the University of Chicago Press, 2015.

SCHÉRER, R. L'écosophie de Charles Fourier: deux textes inédits. Paris: Anthropos, 2001.

SILVA, D. M. da. Mouvements-réseau: les interconnexions entre technologie, environnement et vie sociale dans l'espace urbain. Sociétés, v. 3, n. 145, p. 75-84, 2019.

SILVA, A. de S. E. From cyber to hybrid: mobile technologies as interfaces of hybrid spaces. Space and Culture, v. 9, n. 3, p. 261-278, 2006.

SLOTERDIJK, P. The Anthropocene : A Process-State on the Edge of Geohistory. In: KLINGAN, K.; SEPAHVAND, A.; ROSOL, C.; SCHERER, B. M. (Org.). Textures of The Anthropocene: Grain Vapor Ray. Cambridge, Mass: MIT Press, 2015.

STEFFEN, W. et al. The Anthropocene: conceptual and historical perspectives. Philosophical Transactions of the Royal Society of London A, v. 369, n. 1938, p. 842-867, 2011.

STENGERS, I. Au temps des catastrophes. Résister à la barbarie qui vient. Paris: La Découverte, 2009.

VATTIMO, G. A sociedade transparente. Lisboa: Relógio d’Água, 1992.

ZIELINSKI, S. Arqueologia da mídia em busca do tempo remoto das técnicas do ver e do ouvir. São Paulo: Annablume, 2006.

Dossiê 0 Pensamento Ecológico - https://revistaecopos.eco.ufrj.br/

ISSN $2175-8689$ - v. 23, n. 2, 2020

DOI: 10.29146/eco-pos.v23i2.27530 